OPEN ACCESS

Edited by:

Junjie Xiao,

Shanghai University, China

Reviewed by:

Guoping Li,

Massachusetts General Hospital,

Harvard Medical School,

United States

*Correspondence:

Boris Schmitz

Boris.schmitz@ukmuenster.de

Specialty section

This article was submitted to

General Cardiovascular Medicine,

a section of the journal

Frontiers in Cardiovascular Medicine

Received: 11 June 2018

Accepted: 28 June 2018

Published: 16 July 2018

Citation:

Schmitz B and Brand S-M (2018)

Commentary: MicroRNA-221/222

Family Counteracts Myocardial

Fibrosis in Pressure Overload-Induced

Heart Failure.

Front. Cardiovasc. Med. 5:95.

doi: 10.3389/fcvm.2018.00095

\section{Commentary: MicroRNA-221/222 Family Counteracts Myocardial Fibrosis in Pressure Overload-Induced Heart Failure}

\author{
Boris Schmitz* and Stefan-Martin Brand \\ Institute of Sports Medicine, Molecular Genetics of Cardiovascular Disease, University Hospital Muenster, Muenster, Germany
}

Keywords: heart failure, remodeling, micoRNAs, cardiac hypertrophy, exercise

\section{A commentary on}

MicroRNA-221/222 Family Counteracts Myocardial Fibrosis in Pressure Overload-Induced Heart Failure

by Verjans $R$, Peters T, Beaumont FJ, van Leeuwen R, van Herwaarden T, Verhesen W, et al. (2018). Hypertension 71:280-8. doi: 10.1161/HYPERTENSIONAHA.117.10094

Recently Verjans et al. (1) investigated the role of microRNA (miRNA)-221 and -222 in heart failure and cardiac remodeling. Using endomyocardial biopsies of patients with dilated cardiomyopathy (DCM) the authors found significantly reduced levels of miRNA-221-3p and -222-3p in patients with severe fibrosis compared to those with non-severe fibrosis. Subsequent investigations in mice suggested that inhibition of miRNA-221 and -222 aggravated pressure overload-induced heart failure potentially by targeting components of the transforming growth factor-beta (TGF-beta) pathway. The authors concluded that delivery of synthetic miRNA-221/-222 might be a future treatment option in heart failure (1). Since these results are partly in contradiction with earlier reports suggesting that elevated levels of miRNA-221 and -222 may actually cause heart failure, it might be worthwhile to look at the history of miRNA-221/-222 research in heart failure.

More than a decade ago, Sayed et al. (2) performed an early miRNA microarray screening of RNA extracted from mice hearts in which cardiac hypertrophy had been induced by transverse aortic constriction. At that time, the applied Atactic $\mu$ Paraflo microfluidics chip covered 334 mature miRNA probes (2), whereas today, with the latest miRBase version 22 release (www. mirbase.org/, GRCm38, March 2018) (3) 2,013 mature mouse miRNAs can be screened. The group detected miRNA-221 and -222 (among others) significantly upregulated 7-14 days postintervention in hyperthrophic mice compared to control (2). Shortly after, these results were confirmed in an independent microarray approach by another group who induced pressure overload in mice by thoracic aortic banding (4). Based on these findings, Wang et al. (5) started to analyse miRNA-221 in cardiac hypertrophy including the generation of transgenic mice for the constitutive cardiac-specific overexpression of miRNA-221 (6) and miRNA-222 (7). Their studies suggested that (separate) overexpression of miRNA-222 and miRNA-221 caused cardiac dysfunction and heart failure leading to the conclusion that miRNA-221 and -222 are potential therapeutic targets for heart failure $(6,7)$, indicating that targeted reduction of the miRNAs would be favorable. 
Additional evidence, especially for the role of miR-222 in cardiac hypertrophy and heart failure, came from an independent array-based screening (TaqMan rodent miRNAarray, $\mathrm{A}+\mathrm{B}$ set v3.0, 641 mmu-miRNAs) of cardiac miRNAs from mice subjected to a ramp swimming exercise or voluntary wheel running model (8). The authors identified 16 regulated miRNAs (validated over both models) involved in physiological cardiac growth including miR-222 but not miR-221. Furthermore, suppression of miRNA-222 during exercise by LNA-antimiRNA-222 injection prevented cardiomyocyte growth and inhibited cardiac hypertrophy and the overall increase in heart size. Treatment of sedentary mice with anti-miRNA-222 for 3 weeks did not affect heart weight (8). Subsequently, the group generated inducible cardiomyocyte-specific miRNA222 transgenic mice in which they induced miRNA-222 overexpression at week 10-12 for 4 weeks. This led to a $\sim 6.5$-fold increase of cardiac miRNA-222 but did not affect heart size and cardiac function despite significantly higher miRNA-222 levels compared to exercise-induced miRNA-222 levels (2.8-fold in running model). The authors concluded that miRNA-222 is necessary for cardiac hypertrophy in exercise but is not sufficient to cause the exercised-heart phenotype (8).

\section{REFERENCES}

1. Verjans R, Peters T, Beaumont FJ, van Leeuwen R, van Herwaarden T, Verhesen W, et al. MicroRNA-221/222 family counteracts myocardial fibrosis in pressure overload-induced heart failure. Hypertension (2018) 71:280-8. doi: 10.1161/HYPERTENSIONAHA.117.10094

2. Sayed D, Hong C, Chen IY, Lypowy J, Abdellatif M. MicroRNAs play an essential role in the development of cardiac hypertrophy. Circ Res. (2007) 100:416-24. doi: 10.1161/01.RES.0000257913.42552.23

3. Kozomara A, Griffiths-Jones S. miRBase: annotating high confidence microRNAs using deep sequencing data. Nucleic Acids Res. (2014) 42:D68-73. doi: 10.1093/nar/gkt1181

4. Tatsuguchi M, Seok HY, Callis TE, Thomson JM, Chen JF, Newman $\mathrm{M}$, et al. Expression of microRNAs is dynamically regulated during cardiomyocyte hypertrophy. J Mol Cell Cardiol. (2007) 42:1137-41. doi: 10.1016/j.yjmcc.2007.04.004

5. Wang C, Wang S, Zhao P, Wang X, Wang J, Wang Y, et al. MiR-221 promotes cardiac hypertrophy in vitro through the modulation of p27 expression. J Cell Biochem. (2012) 113:2040-6. doi: 10.1002/jcb.24075

6. Su M, Wang J, Wang C, Wang X, Dong W, Qiu W, et al. MicroRNA221 inhibits autophagy and promotes heart failure by modulating the p27/CDK2/mTOR axis. Cell Death Differ. (2015) 22:986-99. doi: $10.1038 /$ cdd.2014.187

7. Su M, Chen Z, Wang C, Song L, Zou Y, Zhang L, et al. Cardiac-specific overexpression of miR-222 induces heart failure and inhibits autophagy in mice. Cell Physiol Biochem. (2016) 39:1503-11. doi: 10.1159/000447853

8. Liu X, Xiao J, Zhu H, Wei X, Platt C, Damilano F, et al. miR-222 is necessary for exercise-induced cardiac growth and protects against pathological cardiac remodeling. Cell Metab. (2015) 21:584-95. doi: 10.1016/j.cmet.2015. 02.014
However, both groups presented data suggesting that miRNA222 acts partly through the deactivation of cyclin-dependent kinase inhibitor p27(KIP1) $(7,8)$ which induces cell cycle arrest (9).

Taken together, it seems likely that miRNA-222 may indeed have cardioprotective effects in adult animals (and potentially humans) and in certain disease conditions such as heart failure rather than being detrimental. Several studies have shown that miRNA-222 may be specifically induced by physical exercise not only in athletes (10-12) but also in moderately trained healthy individuals (13) as well as patients with heart failure (8). It may therefore be of interest to initiate further studies to investigate to what extend miRNA-222 might be a useful marker to monitor cardioprotective exercise in primary and secondary prevention and rehabilitation of heart failure patients.

\section{AUTHOR CONTRIBUTIONS}

BS has fully reviewed the original article, drafted the commentary, reviewed, and approved the final manuscript. $\mathrm{S}-\mathrm{MB}$ has also reviewed the original article, assisted in drafting the commentary, reviewed and approved the final manuscript.

9. Kim YK, Yu J, Han TS, Park SY, Namkoong B, Kim DH, et al. Functional links between clustered microRNAs: suppression of cell-cycle inhibitors by microRNA clusters in gastric cancer. Nucleic Acids Res. (2009) 37:1672-81. doi: 10.1093/nar/gkp002

10. Baggish AL, Hale A, Weiner RB, Lewis GD, Systrom D, Wang F, et al. Dynamic regulation of circulating microRNA during acute exhaustive exercise and sustained aerobic exercise training. J Physiol. (2011) 589:3983-94. doi: 10.1113/jphysiol.2011.213363

11. Ramos AE, Lo C, Estephan L, Tai YY, Tang Y, Zhao J, et al. Specific circulating microRNAs display dose-dependent responses to variable intensity and duration of endurance exercise. Am J Physiol Heart Circ Physiol. (2018). doi: 10.1152/ajpheart.00741.2017. [Epub ahead of print].

12. Wardle SL, Bailey ME, Kilikevicius A, Malkova D, Wilson RH, Venckunas T, et al. Plasma microRNA levels differ between endurance and strength athletes. PLoS ONE (2015) 10:e0122107. doi: 10.1371/journal.pone.0122107

13. Schmitz B, Rolfes F, Schelleckes K, Mewes M, Thorwesten L, Krüger M, et al. Longer work/ rest intervals during high-intensity interval training (HIIT) lead to elevated levels of miR-222 and miR-29c. Front Physiol. (2018) 9:395. doi: 10.3389/fphys.2018.00395

Conflict of Interest Statement: The authors declare that the research was conducted in the absence of any commercial or financial relationships that could be construed as a potential conflict of interest.

Copyright (C) 2018 Schmitz and Brand. This is an open-access article distributed under the terms of the Creative Commons Attribution License (CC BY). The use, distribution or reproduction in other forums is permitted, provided the original author(s) and the copyright owner(s) are credited and that the original publication in this journal is cited, in accordance with accepted academic practice. No use, distribution or reproduction is permitted which does not comply with these terms. 